\title{
The non-verbal communication in handover situations are the spice between the lines, to understand the severity of the patient's condition
}

\author{
Hanna Engstrand ${ }^{1}$, Janet Mattsson ${ }^{* 2}$ \\ ${ }^{1}$ Department of Clinical Science and Education, South Central Hospital, Sweden \\ ${ }^{2}$ Department of Health and Technology Development, Red Cross University College, Sweden
}

Received: October 25, 2016

Accepted: December 1, 2016

Online Published: December 14, 2016

DOI: $10.5430 /$ jnep.v7n5p1

URL: http://dx.doi.org/10.5430/jnep.v7n5p1

\begin{abstract}
Aim: The aim of this study was to investigate emergency nurses' experiences of verbal handover from emergency medical services and through these experiences uncover patient safety issues in the handover situation.

Methods: Design: The design is qualitative inductive and aims to deepen the understanding of the handover situation and to uncover the nurses' experiences in such a situation. Methods: A qualitative research process which takes its departure in patient safety theory. Nine informants were interviewed and a content analysis was applied.

Results: The results show that a lack of structure, lack of seeing the non-verbal communication, the nurses' own requirement for full control and the lack of active listening involves patient safety risks. Emergency nurses want a handover that is personal and provides a comprehensive picture of the patient to support, deepen or contradict the verbal handover given.

Practical implications: The non-verbal communication in the handover situation is key to understand the severity of the situation and give the nurses profane knowledge how to prepare the continuing nursing care. To further support the understanding of the situation, information should be presented in chronological order.
\end{abstract}

Key Words: Communication, Handover, Patient safety

\section{INTRODUCTION}

Patient safety concerns all health care personnel and many things has been done to improve the safety at our hospitals, nationwide. However, the patients are still at risk especially in handover situations. As healthcare becomes more complex, it becomes more difficult to grasp and understand regardless of a safe handover process are implemented at the ward. The emergency department nurse is one of the key persons in a handover situation with patients arriving at the emergency department by ambulance. These patients are especially vulnerable as they often arrive acutely with little or no previous information related to their condition. The key to safety in a handover lies within the communication in the situation. However, nurses experience a lack of important information, jeopardizing their continuing nursing care due to communication failures.

\subsection{Patient safety}

In a global perspective, patient safety has become a major issue. World Health Organization (WHO) defines patient

\footnotetext{
* Correspondence: Janet Mattsson; Email: Janet.mattsson@ki.se; Address: Department of Health and Technology Development, Red Cross University College, Sweden.
} 
safety as "the prevention of errors and adverse effects to patients associated with health care". [1] Since 2002, WHO's member states work together to improve patient safety and in 2004 a program called WHO Patient Safety was launched to increase patient safety worldwide. US based Institute for Healthcare Improvement ${ }^{[2]}$ has worked more than 25 years to solve problems in health care globally. Australia also has patient safety on the agenda. ${ }^{[3]}$ In Sweden patient safety became a major issue when a review of 19,000 admissions in hospital care showed that $10 \%-15 \%$ of the hospitalized patients suffered harm. ${ }^{[4]}$ These injuries result in almost one and a half million extra hospital days a year, to the cost of approximately eleven billion (DOLLARS? EURO?) each year, of which just over eight billion is considered damage possible to avoid. From a Swedish perspective, it is most important to enhance the quality of the patient safety both to prevent avoidable injuries and lower the cost of health care. ${ }^{[5]}$ In 2010, the current Swedish Patient Safety Act ${ }^{[6]}$ was introduced. The law defines health injurie as a physical or mental suffering, injury, disease or death that would have been avoidable. The law states that health professionals have a duty to maintain a high patient safety. Which from a patient perspective means less suffering for the individual patient and their family, as well as an economic gain for society. ${ }^{[4]}$ Lack of communication is a known and severe problem that put patients at risk of becoming injured due to communication errors, misreadings, inaccurate estimates or misreportings. ${ }^{[7]}$ One of the most vulnerable patient safety situations within health care involving communication, are transfer situations, as they might jeopardize patient safety due to a lack of communication when patients and/or information transferees from one career to another. ${ }^{[3]}$ As healthcare becomes more complex it becomes more difficult to grasp, and the health care providers who depend on each other need to communicate complex matters in a clear and understandable way. This study takes its departure from a patient safety perspective as it investigates everyday handover situations between paramedics and emergency department nurses.

\subsection{Communication}

As stated above many mistakes occur in healthcare due to lack of communication. ${ }^{[3,8]}$ To communicate means to send messages or signs as symbols of a thought or an idea that recipients in turn interprets, even though most of the communication is non-verbal. ${ }^{[9]}$ Hopefully the recipient obtains the same perception of the idea as the transmitter. Communication is thus a complex process where people are talking to each other and act as both transmitters and receivers at the same time. However, the communication process from the recipient's perspective is not passive as recipients actively design their own understanding of what is communicated and what it means. ${ }^{[9]}$ Communication between health care professionals is most fragile during shift changes, patient transfer between departments, heavy workloads, and at unsocial hours. ${ }^{[10]}$ Therefore, clear communication is vital to conduct an effective and safe care. At the handover of a patient between health professionals, the communication between them are a crucial part of the handover and lack of communication, verbal or written, might put the patient at risk. ${ }^{[11]}$ Examples of events that can occur when incorrect or unclear communication are at hand, is that the patient is transferred to the wrong department or that the recipient gets the wrong idea about the patient's diagnosis and the patient thereby risk getting the wrong treatment, or none. A structure for a good rendition of a patient's condition, means that patient safety is secured and that staff receive good knowledge about the patient. Ultimately, quality of care is enhanced and staff stress level decreases. ${ }^{[8]}$

\subsection{Handover in the emergency department}

In the emergency department, verbal reports from the paramedics to the emergency staff are frequently recurring. ${ }^{\text {[2] }}$ However, the quality of reporting between the paramedics and hospital staff varies, depending on the language and choice of words used, the method used for the transmission and the reporting of the patient, and the level of knowledge and experience of those involved. ${ }^{[12]}$ Since each handover situation increases the risk of patient injury a patient is exposed to potential patient safety risks, ${ }^{[11]}$ and for an over-reporting to be safe there are many factors involved, such as how to communicate with each other in a way that important information will be acknowledged, which structure is used, what kind of information the structure supports, how work situations are experienced and individual feelings of responsibility for ones' actions. ${ }^{[11]}$ Lack of structure and guidelines on how the reporting should be done also affect the quality negatively. ${ }^{[10,13]}$ Since information is the cornerstone of continuity and structure, ${ }^{[2]}$ structured communication tools are used to effectively communicate about a patient between health team members in an understandable and correct way. ${ }^{[14]}$ For example, communication tool SBAR, (Situation Background Acute Recommendation) originated in the US Navy and the Crew Resource Management tool from the airline industry, are used in health care settings. ${ }^{[14]}$ Originally the SAMPLE tool (Signs, symptoms Allergies Medication Past medical history Load oral intake) was a way for ambulance and emergency care personnel to interview a patient, structuring the handover of the patient. ${ }^{[15]}$ Another template for transferring information between patient care professionals is MIST (Mechanism of injury Illness Signs Treatment), also originating from the military. ${ }^{[16]}$ The core of the various structures of reporting is to obtain specific information in a structured 
way. In Sweden SBAR was launched at a patient safety conference in 2010 by the Swedish Association of Local Authorities and Regions, ${ }^{[17]}$ which may have led to that SBAR has become widely accepted as a structured communication model. Professionals having good knowledge of the structure speak without interruptions since recipients know that information is given in a certain order, and he or she understands what kind of information will be communicated and in what order. $^{[14]}$

It is of importance to uncover how paramedics and emergency department nurses communicate, and what they do to maintain a patient safe verbal handover. In the encounters between patients and careers, unpredictable human differences are involved, which can mean that the difference between successful treatment and life-threatening situations can be fractional.

\subsection{Aim}

The purpose of this study was to investigate emergency nurses' experiences of verbal handover situations from paramedics and through these experiences uncover patient safety issues in the handover situation.

\section{METHOD}

The design of this study is qualitative and aims to deepen the understanding of the handover situation and to uncover nurses' experiences in such situations. ${ }^{[18,19]}$ The qualitative approach in this study is expected to provide further knowledge of emergency nurses' experiences of verbal handover situations and uncover patient safety issues in the everyday situation, as handover situations are.

\subsection{Participants and setting}

The study took place between September and December 2015 at an emergency department in central Sweden with a patient influx averaging 170 per day, distributed among 26 nurses. The potential informants, selected by convenient sampling, consisted of 26 registered nurses employed at the emergency department. Information about the purpose of the study was sent to informants via email and close after the first message a new contact with potential informants was taken, to ensure that they received the information, investigate whether there were issues that needed answering and determine the time and place for the interview if they were willing to participate. A total of nine informants were selected from registered nurses who were interested of participating in the study and had worked two years or more at the ward and currently were employed full time.

Published by Sciedu Press

Published by Sciedu Press

\subsection{Data collection, interview and procedure}

Semi-structured interviews with open questions were selected as data collection method, ${ }^{[20]}$ since it can generate rich narratives from informants. The interviews were recorded digitally and then verbatim written. The interviews took place at the informants' workplace and were 45 minutes to 90 minutes long. The informants chose where they wanted to be interviewed, as we wanted them to feel as comfortable as possible in the interview situation. ${ }^{[20]}$ A test interview was conducted to test the interview questions usability. The interview guide was deemed satisfactory and no adjustment was made, the test interview was included in the study. The interviews all began with the same questions: How many years have you been a nurse? And how many years have you worked in this emergency department? After these introduction questions informants were asked to describe their experiences of a good verbatim handover situation and a non-satisfactory handover situation from the paramedics.

\subsection{Data analysis}

All interviews were transcribed verbatim immediately after the interview, with the interview still fresh in memory. This facilitated the understanding of the meaning of what was told and how it was told, with facial expressions and gestures. ${ }^{[20]}$ After transcription, the interview was sent to each informant for them to read and approve or disapprove if the content was consistent with what they said during the interview. All informants approved the content. The interviews were then analyzed using qualitative content analysis guided by the work of Granheim and Lundmans ${ }^{[21]}$ description of content analysis. The analysis started with reading and rereading the interviews on several occasions. The purpose of this was to get an overall feel for the text, what was said and what was the meaning in the interview. Then specific parts of the text were selected, meaning units, that contained information relevant to the study. Then meaning units were condensed and the condensed text was grouped into subcategories with each subcategory reflecting the central meaning of each interview. The subcategories were then re-analyzed and compiled to categories, which each category expressing something specific about the content. In the last step of the analysis meaningful units, subcategories and categories are analyzed to find the latent content and, based on the findings themes emerged. The analysis process is not a straight forward process as described above, it is an iterative process going back and forth.

\subsection{Ethical considerations}

Permission to conduct the study has been requested and received by the head of the emergency department where the study was conducted. According to Swedish law and the Act 
on Ethical Review of Research Involving Humans ${ }^{[22]}$ and the Personal Data Act ${ }^{[23]}$ an ethical review was not needed, as the informants were all 18 years of age and able to accept or decline participation in the study. Informed consent was obtained from all informants after they had received information about the study both orally and written. The informants were also informed that participation was voluntary and that they at any time could abort their participation in the study without questions being asked. Each informant has confirmed their participation by signing a paper. ${ }^{[24]}$ To strengthen the study's reliability, each informant had the opportunity to approve or disapprove their own interview.

\section{Results}

The overall result consists of four themes. Grasping the whole, elucidating the information given by the nonverbal communication, having eye contact with the paramedic, seeing the patient's posture and hearing sounds from the patient in the handover situation as crucial to how the verbatim handover was received and understood. Sense of time, elucidating the timeframe from the call to the dispatch Centre to the handover at the emergency department. It was important that the handover conveyed what had happened and changes that had occurred to the patient in a time structured way. The structure of the handover was not important but the timeline and the timeframe enclosing the sequences of every change in the patients' condition needed to be conveyed to underpin the understanding of what was at hand. Strive to control, this theme conveyed a contradiction as it highlighted the strive of being in control as a hindrance of controlling the situation. The eagerness of doing right and being of use to the patient became a hindrance as demands from the context as phone calls, other work-related issues were demanding attention and control was lost. In the last theme, transmission, personal preconceptions of the patient and the patient's situation were conveyed, rather than the professional assessment of the patient's needs. This could pose a barrier to becoming treated sufficiently as it blurred the recipients own understanding of the patient's needs.

It was thus important information conveyed between the paramedic that handed over the patient and the recipient nurse through body language, facial expressions and intonation of words. This was information never verbalized or documented but that had a decisive influence on how the recipient nurse perceived and understood the patient's condition and prepared how to intervene with the patient.

\subsection{Grasping the whole}

In this theme the nonverbal information emerged as a bearer of crucial information in the handover situation, for the re- cipients understanding of the patient and the continuous care. A verbal handover situation gives the recipient possibilities to weigh oral information given, through a body posture, eye contact and facial expression, supporting the spoken words. Body language can also reinforce the impression of what is said as the paramedic handing over the patient might stand up with a tense body and uses fast movements, might tremble a little in the hands if the patient is unstable. In this way, the recipient nurse understands rapidly if they will receive a report on a stable or unstable patient and can prepare to act accordingly. The following excerpts highlight this:

"Why the patient is here, it is important to know. But if there is something that stands out with the paramedics' way of acting in the handover situation, somethings that differ, something that they say, their own thoughts. That is important to me" (I, 6).

If the handover situation includes being with the patient additional nonverbal information is disclosed as the recipient can see, hear, touch and smell the patient, as well as starting to build a relationship with the patient. Also, the feeling of the rigor in the prior investigation of the patient's needs, builds trust for how to understand and act upon the information given. The following excerpt highlights this:

"I feel that it is an advantage to be with the patient in a verbal handover situation, one can also look at the patient and listen to the patient during the handover. The patient can say something if something is wrong, at once. And you will know" (I, 8).

\subsection{Sense of time}

This theme elucidates the importance of a verbal handover with a beginning and an end, in chronological order but also the importance of giving the timeframe enclosing the sequences of every change in the patient's condition that might have occurred during transport, to facilitate a broader scope of the verbal handover. A structured report means that it follows a certain path of time, giving the recipient a time frame to relate to, starting with why the patient contacted the dispatch Centre and what happened next, which steps were taken, why, if there are any contextual factors connected such as other transports from a trauma scene and in the end a concluding statement of how the patient is doing right now at the handover. The following excerpt highlights this:

"A structured hand over, so we can, say, it is the best, so that in all cases, there is a time line in it all. Otherwise it can become jumpy, back and forth, and then you have no track at all about what was said from the beginning" (I, 5). 
"A structured hand over, as SBAR is actually pretty good. When you start with what happened and the situation. When you go from, what happened, and then structure it as SBAR, then you know what to bring forward in the handover"(I, 3).

A chronological order and a dialogue allows the timeframe to be present and gives a picture of the entire event that supports memory. One part of a structured report is to report directly to the recipient without several participants involved. otherwise the essence of the patient's story might disappear and uncertainty will arise.

\subsection{Strive to control}

In this theme a contradiction emerged as the efforts to be on top of the situation lead to lack of active listening/concentration and subsequently to missed information. The fear of losing control and the context around inviting to do several things simultaneously inhibited the prioritizing in the handover situation. The following excerpts highlights this:

"A good reporting is when you can be yourself with the one who has cared for the patient in the ambulance, when we can get to have your own time if you say so, without other factors around that bothers you, so you can focus on what they say"(I, 2).

"And if there are a lot of patients, then, you do not have time to focus on what they say. Well, when it's very stressful around, that's when it's hard" (I, 1).

Stress can cause the recipient to hear what is said but not actively listening as there is high activity at the ward. The lack of considerations and respect for one's responsibilities between staff is a sign of a caring culture that might jeopardize the understanding of what is said in the verbal handover and subsequently becoming a patient safety risk.

\subsection{Transmission}

This theme conveyed the asymmetry in the relation career-patient, as the personal view on the patient were influencing the verbal handover and thus the understanding of the patient's condition. The following excerpts highlights this:

"When they put forward assumptions as, well, you hear something like, you know, he has no home, he is certainly an alcoholic. Or you just assume something or take it for granted, that it is right because the paramedic told you. And then you find out maybe that was not the case, he may not have drunk alcohol, he might have diabetes" (I, 4).

"Paramedic came and basically let the papers on the desk and said, here we come with a whining bitch, we could not leave her at home. Uhm, and then they went away. I think, I dare not say whether they had taken the vital signs in the ambulance or not, but they had put a diagnosis on the lady, who later turned out to have a Cullum. But it was very clear, whining bitch, and then not much more. They did not really know why the patient wanted care, they told me why they felt they could not leave the lady at home. Um, and I think it was mostly a question of attitude"(I, 6).

The excerpts above show lack of respect for the caring values, it also elucidates how one's own preconceptions relate to and influence one's professional role, letting the choice of examination and treatment start from one's own assumptions about the patient, not in the patient's story. A view on the patient that may pass on to the next caregiver and cause severe damage.

\section{Discussion}

Designing a study always means choosing ways of collecting data, consider how to do a rigorous analysis and contribute to the field of nursing science in different ways. However, there is no study that can cover everything and there will always be things that could have been done in other ways. Limitations are present in every study and in this study the data collection took place at a hospital outside the larger cities in Sweden. This can have impact on the injuries seen and handled by nurses at the emergency ward. The workplace might also have more women employed and be influenced of a caring culture diverse from the larger cities in Sweden, which can have implications on how communication in handover situations is done. None the less, the purpose of this study was to investigate emergency nurses' experiences of verbal handover situations from paramedics and through these experiences uncover patient safety issues in the handover situation. We considered a qualitative design with semi-structured interviews were the most appropriate research method to answer the aim of the study. The advantage of using semi-structured interviews as a data collection method is its flexibility to the situation. ${ }^{[20]}$ Open questions allow for the informant's experiences to arrive. We could have used informal conversations or focus group interviews but 
for rigor and ethical considerations we found those methods to be limited as data collection methods as there might be a risk that informants feel inhibited to talk about their experiences in a group. ${ }^{[25]}$ The choice of informants was to obtain as much information as possible during the interviews. ${ }^{[19]}$ To ensure rigor in the data analysis the first author analyzed the data with help from the second author and two outsiders reviewed the analysis to strengthen the credibility. ${ }^{[19]}$

The amalgam of the results in this study elucidated that handover situations are complex multidimensional situations, requiring specific knowledge that uncovers salient information in the interaction with the patient in a specific context. Requiring certain skills and involvement in the situation. Body language speaks its own language; it fills the verbal information in a way that is unique. Which implies that a verbal handover eye to eye is crucial in understanding the whole situation as non-verbal communication from the paramedic as well as from the patient underpins the understanding of what is at hand, what path the recipient nurse should prepare for the patient. The understanding of the situation and preparedness of how it can evolve is a very strong patient safety issue, as misunderstandings and erroneous reactions occur in situations where verbal communication is transmitted without any nonverbal communication involved, it is not just what is said but also how it is said that is important. ${ }^{[26,27]}$ Bruce and Suserud ${ }^{[28]}$ argues that the verbal reporting could be key for a deeper understanding about the patient as it contains information and provides a comprehensive picture of the patient's situation and accordingly saves time for the recipient nurse and thereby streamlines nursing care. Verbal handover situations are a prerequisite for dialogue, where empathy and mutual understanding can be formed. ${ }^{[29]}$ This is important to highlight from a patient safety perspective since much of acute care is about gaining time, time that can be spent on stabilizing and treating the patient.

It is also important for the understanding and continued nursing care to make handovers structured starting with a clear beginning and a clear end, corresponding to the actual time frame from when the paramedics arrive on the scene until the patient is in the emergency room. This study reveals that a time frame provides an understanding of what happened, when it happened, and more importantly it gives a frame of time to relate to in respect of how fast things are changing with this particular patient and consequently how much time nurses have to prepare for interventions. Structured over-reporting are widely used and aims to provide a systematic transfer of information between paramedics and emergency personnel. ${ }^{[8,12,29]}$ Regardless of which overreporting template is used information will be understood and interpreted in different ways depending on who delivers and who receives information, ${ }^{[12]}$ and a vague over-reporting may jeopardize patient safety due to the risk of misinterpreting information. This study suggests that patient safety would be strengthened if the reports became structured in time and paid attention to the dimension of the non-verbal communication as well. For instance, can training and practice with a default structured handover template with emphasis on the part where you check the understanding of the information transferred, the spoken and the non-verbal, correctly be a way to improve reporting and ensure that all the information contained in the template are included in the reporting? A default handover template does not guarantee that one says everything that one ought to say but it helps to structure the report. On the other hand the results uncovered a paradox as it revealed that trying to control everything about the patient and everything in the context surrounding the patient, with the aim to do whatever necessary for the patient, led to the inability to stay focused and actively listen to the verbal handover. It became counterproductive and jeopardized the patient, instead of as intended performing multiple tasks simultaneously and getting control of the situation. To focus on practical tasks rather than listen actively and try to understand what the things said means might jepordize the patients safety. ${ }^{[29]}$ The reason for losing focus and active listening might be due to the expectations, one's own or others, and because of this intrinsic or extrinsic expectation mentally preparing for the next verbal handover instead of being with the patient at hand. In acting so important information fails to be recognized. ${ }^{[8]}$ Although the workload can become a risk in a handover situation ${ }^{[7,8,12,29]}$ it might be reduced if there is a functioning teamwork that is trained in handling acute situations on a regular basis. To be prepared for the unknown and work in a well-functioning team will add value to the patient as everyone knows what to do, when to do it and how to do it, and most of the reasons for having to control everything yourself might vanish. As mentioned earlier, lack of communication is a contributing factor to accidents within the health care system. ${ }^{[7,8]}$ But also a lack of respect among staff or hierarchical structures can become patient safety issues as unreflected and unnecessary disturbances of a colleague in the middle of a verbal handover situation can cause harm to the patient. Hierarchy is an inevitable part of care and nurses do not always dare to contradict the orders from those who are higher up in the hierarchy, like physicians. ${ }^{[30,31]}$ It might not be that the physician considers his or her information as more important, it might be that the hierarchy simply allows physicians to interrupt the conversation between staff who are at a lower level of hierarchy. What is more worrying is how the influence of personal preconceptions and attitudes towards the patient interacted with the way the patient was 
cared for and the content communicated in the verbal handover. If the patient's condition were of a less acute matter, the patient might be handed over by another paramedic than the one that cared for the patient during transport. Studies show $^{[28,32]}$ that patients who needed medical treatment got handed over in a more sufficient way, since patient with less medical needs were seen less engaging which influenced the handover situation negatively. ${ }^{[28,32]}$ This results uncover a lack of professionalism from the paramedics which can cause the staff in the emergency room to be negatively affected by the attitude and approach the patient in an insufficient way. As previously mentioned, all health care personnel should conduct health care on equal terms and every person's dignity should be respected. ${ }^{[33]}$

\section{RelevanCE FOR Clinical PRACTICE}

This study reveals shortcomings in patient safety when the importance of the non-verbal communication isn't acknowl- edged as a dimension of specific information alongside the verbal information given. When nonverbal communication is neglected handover reports are not functioning optimally. On the other hand, findings can be used to enhance patient safety by improving the combination of verbal and non-verbal communication as it is key to a deeper understanding of the whole situation. Also, a handover template that supports the time frame could be used to clarify what is done and in which order. This supports the understanding of what is at hand and what is expected to be done in the near future to give a good nursing care. This knowledge can contribute to less suffering for the patient and less costs for both the individual and society.

\section{CONFLicts OF INTEREST Disclosure}

The authors declare that there is no conflict of interest.

\section{REFERENCES}

[1] WHO. Patient Safety. Geneva: World Health Organization; 2014.

[2] Jenkin A, Abelson-Mitchell N, Cooper S. Patient Safety. Cambridge: Institute for Healthcare Improvement. Patient handover: Time for a change? Accident and Emergency Nursing. 2007; 15(5): 141-7. PMid:17618118 https://doi.org/10.1016/j . aaen. 2007.04 .004

[3] Aldrich R, Duggan A, Lane K, et al. Isbar revisited: Identifying and solving barriers to Effective clinical handover in inter-hospital transfers. 2009.

[4] SKL. Patientsäkerhet lönar sig-kostnader för skador och vårdskador i slutenvården år 2013 (Patient safety pays off. Costs of injuries and health damage in the inpatient 2013) Stockholm: SKL (Swedish Association of Local Authorities and Regions). 2014.

[5] Welfare NBoHa. Förslag till nationell strategi för ökad patientsäkerhet (Draft national strategy for improving patient safety). Stockholm: Socialstyrelsen (The National Board of Health and Welfare). 2012.

[6] Patientsäkerhetslag (Patient Safety Act), Pub. L. No. 2010.

[7] Ödegård S. Safe care - patient injuries, reporting and prevention. Gothenburg: Nordic School of Public Health. 2006.

[8] Talbot R, Bleetman A. Retention of information by emergency department staff at ambulance handover: do standardised approaches work? Emergency Medicine Journal. 2007; 24(8): 539-42. https : //doi.org/10.1136/emj.2006.045906

[9] Nilsson B, Waldemarson A. Communication: interaction between people. Lund: Studentlitteratur; 2007.

[10] Manser T, Foster S. Effective handover communication: an overview of research and improvement efforts. Best Pract Res Clin Anaesthesiol. 2011; 25(2): 181-91. https://doi.org/10.1016/j.bp a. 2011.02.006

[11] Dyrholm-Siemsen I, Dyrløv-Madsen M, Funck-Pedersen L, et al. Factors That Impact on the safety of patient handovers: an interview study. 2012: 439-48.

[12] Bost N, Crilly J, Patterson E, et al. Clinical handover of patient arriving by ambulance to a hospital emergency department: A qual- itative study. International Emergency Nursing. 2012; 20: 133-42. PMid:22726945 https://doi.org/10.1016/j.ienj . 2011.10 .002

[13] Ye K, Taylor D, McD. Knott J, et al. Handover in the emergency department: Deficiencies and adverse effects. Emergency Medicine Australasia. 2007; 19: 433-41. PMid:17919216 https://doi.or $\mathrm{g} / 10.1111 / \mathrm{j} .1742-6723.2007 .00984 . \mathrm{x}$

[14] Wallin C, Thor J. SBAR-modell för bättre kommunikation mellan vårdpersonal (SBAR-model for better communication between health professionals). Läkartidningen. 2008; 105(26): 1922-5. PMid:18681371

[15] Dalton A, Adhesives D, Mistovich J, et al. Advanced Medical Life Support. New Jersey: Pearson Education. 2007.

[16] Evans S, Murray A, Patrick I, et al. Clinical handover in the trauma setting: a qualitative study of paramedics and trauma team members Quality Safety Health Care. 2010; 19.

[17] SKL. Lägesrapport inom patientsäkerhetsområdet 2014 (Progress in the field of patient safety in 2014). Stockholm: Socialstyrelsen (The National Board of Health and Welfare). 2014.

[18] Polit DB. CT Nursing Research: Generating and Assessing Evidence for nursing practice. . Philadelphia: Lippincott Williams \& Wilkins; 2008.

[19] Henricsson M, Hult B. Theory and Methodology. In: Henricson M, editor. Poland: Sage; 2013. 129-37p.

[20] Danielson E. Qualitative research interview. In: Henricson M, editor. Theory and Methodology. Poland: Sage; 2013.

[21] Graneheim UH, Lundman B. Qualitative content analysis in nursing research: concepts, procedures and measures to achieve trustworthiness. Nurse Educ Today. 2004; 24(2): 105-12. https ://doi .org/ $10.1016 / j$.nedt. 2003.10.001

[22] Act on ethical review of research involving humans. 2003.

[23] Personal Data Act. 1998.

[24] Kjellström S. Research ethics. In: Henricson M, editor. Theory and Methodology. Poland: Sage; 2013. 69-92p. 
[25] Wibeck V. Focus groups. In: Henricson M, editor. Theory and Methodology. Poland: Sage; 2013. 163-73p.

[26] Mehrabian A. Nonverbal Communication. New Jersey: Aldine Transaction; 2007.

[27] Hannawa A. Disclosing medical errors to patient: Effects of nonverbal involvement. Patient Education and Counseling. 2014; 94: 3103. PMid:24332933 https://doi.org/10.1016/j.pec.2013.1 1.007

[28] Bruce K, Suserud BO. The handover process of triage and ambulanceborne patient: the experiences of Emergency nurses. Nursing in Critical Care. 2005; 4(10): 201-9. https://doi.org/10.1111/j.13 62-1017.2005.00124.x

[29] Jensen S, Lippert A, Østergaard D. Handover of patient: a topical review of ambulance crew to emergency department handover. Acta
Anasthesiologica Scandinavia. 2013; 57: 964-70. PMid:23639134 https://doi.org/10.1111/aas. 12125

[30] Cosby KS, Croskerry P. Profiles in patient safety: authority gradients in medical error. Acad Emerg Med. 2004; 11(12): 1341-5. https://doi.org/10.1197/j.aem.2004.07.005

[31] Calhoun A, Boone M, Porter M, et al. Using Simulation to Address hierarchy-related errors in medical practice. The Permanent Journal. 2014; 18(2): 14-20. PMid:24867545 https://doi.org/10.781 2/TPP/13-124

[32] Yong G, Dent AW, Weiland TJ. Handover from paramedics: observations and emergency department clinician perceptions. Emerg Med Australas. 2008; 20(2): 149-55. https://doi.org/10.1111/j . $1742-6723.2007 .01035 . x$

[33] Hälso-och sjukvårdslag (Health Care Act), Pub. L. No. 1982. 